\title{
Oxente Meu Rei: Uma análise dos preconceitos reproduzidos pela propaganda turística do governo da Bahia ${ }^{1}$
}

\section{Oxente Meu Rey: an analysis of prejudice reproduced by advertising tourism government of Bahia}

\author{
Lucas Eduardo Dantas \\ Universidade Estadual do Sudoeste da Bahía (Brasil) \\ lucasvlfsa@gmail.com
}

Recibido: 30 de agosto de 2013 Aceptado y Publicado: 30 de septiembre 2013

\section{Resumen}

Este artigo tem o foco de pesquisar e analisar anuncios televisivos divulgados pelo Governo do Estado da Bahia entre os anos de 2007 e 2013. O objetivo deste artigo é demonstrar os preconceitos e os estereótipos contidos nas ações de publicidade, como: Racismo, xenofobia, exploração sexual infantil, turismo sexual. A Bahiatursa, agência estatal de publicidade baiana é responsável por divulgar uma série de comerciais televisivos e impressos geralmente exibidos no início do ano, época de alta temporada devido a alta estação do verão e aos eventos que acontecem no estado, especificamente na capital, Salvador. Os anúncios chamam os turistas para saborear as belezas que o estado tem, no entanto, boas parte de seus anúncios à atrações da cidade de Salvador. Caracterizamos tal fenômeno como "Soteropolitanização" do estado, onde a imagem vendida pela Bahiatursa resume o estado a somente a sua capital, sendo a fase inicial de surgimento dos estereótipos e preconceitos, logo que o estado possui uma cultura muito ampla e segmentada devido as suas inúmeras regiões geográficas.

Em outro momento do artigo a figura do cidadão baiano é analisada, como forma de identificar o perfil que é difundido, do negro pobre e servil ao turista estrangeiro, sujeito a ser

\footnotetext{
' Artículo producto de una Ponencia presentada en el VI Encuentro Panamericano de Comunicación COM PANAM 2013 celebrado la Escuela de Ciencias de la Información de la Universidad Nacional de Córdoba (Argentina), durante los días 5, 6 y 7 de junio de 2013.
} 
humilhado, mas sempre com o sorriso no rosto para não desapontar aquele que detém o capital financeiro. Outro objetivo é combater o estereótipo da "preguiça" que recai sobre tais cidadãos e a visão que o baiano vive constantemente em festejos.

A questão agravante do turismo sexual também é abordada, muito comum e um dos principais problemas atualmente enfrentados pelo governo. A propaganda de forma subjetiva difunde essa ideia, com enquadramento e fotografias que visam as qualidades sexuais das mulheres baianas e subjuga a sua fisionomia a algo sem importância. Tais preconceitos também se estendem ao imaginário dos turistas moldando a imagem sobre os cidadãos da Bahia no cenário nacional e internacional.

\section{Abstract}

This article is the focus of research and analyze television ads released by the State Government of Bahia between the years 2007 and 2013. The purpose of this article is to demonstrate the prejudices and stereotypes contained in the actions of advertising such as: Racism, xenophobia, child sexual exploitation, sex tourism. The Bahiatursa, advertising Bahia state agency is responsible for publishing a series of television commercials and printed usually appear at the beginning of the year, a time of high season due to the high summer season and the events that happen in the state, particularly in the capital, Salvador. The ads draw tourists to enjoy the beauty that the state has, however, good part of your ads to the attractions of the city of Salvador. We characterize this phenomenon as "Soteropolitanização" state, where the image sold by Bahiatursa summarizes the state to only your capital, with the initial emergence of stereotypes and prejudices, so that the state has a culture very broad and targeted because of their numerous geographic regions.

At another point in the article the figure of the citizen Bahia is analyzed in order to identify the profile that is widespread, the black poor and servile to foreign tourist, subject to being humiliated, but always with the smile on his face not to disappoint one who holds financial capital. Another goal is to combat the stereotype of the "lazy" which falls on such citizens and vision that constantly lives in Bahia festivities.

Palabras Clave: Racismo; xenofobia; turismo sexual; soteropolitanização; publicidade.

Key words: Racism, xenophobia, sexual tourism, soteropolitanização, advertising. 


\section{Introducción}

Como todos sabem, a propaganda é a alma do negócio. É a partir dela que uma empresa quaisquer seja o segmento difunde seu produto, seja ele um bem ou um serviço, é através da propaganda que ele virá a se tornar público e atingirá a gama de consumidores presentes na sociedade. Para se vender algo, é preciso anunciar, publicitar, para que seus clientes em potencial tenham conhecimento do que esta sendo oferecido. Por isso, a propaganda deve ser verídica, fiel ao que se oferece, para não acontecer, como citar o ditado popular, comprar gato por lebre.

No turismo as coisas funcionam desta mesma forma, na venda de um serviço, mas não só isso. As agências de viagem vendem muito mais do que um simples pacote de serviços de férias, eles vendem um sonho, vendem descanso, lazer, vendem até felicidade, me arrisco a dizer. São de certa forma os mediadores entre os sonhos de seus clientes e eles próprios.

Seria perfeito se as coisas funcionassem como esta utopia. Além do que citamos acima, os agenciadores de viagem vendem "indiretamente" muitos mais serviços, ou coisas, ou pessoas até. O mau planejamento dentro do turismo gera disfunções em determinados locais explorados pelo setor que acabam agravando alguns problemas sociais já existentes, abalando a própria estrutura social que é colocada. A xenofobia, por exemplo, é resultado de um preconceito desenvolvido por uma população á respeito de outro grupo social, baseado principalmente em experiências superficiais, às vezes propiciadas pelo turismo. $O$ racismo claro possui uma estrutura histórica muito mais profunda a ampla, mas que também se reproduz dentro desse segmento. Sem contar também com o turismo sexual, disfunção provocada pela atividade turística que existe, mas que nenhum teórico ou profissional da área admite existir de forma estruturada.

Mas, dentro disso tudo cabe uma pergunta interessante: São os turistas e as empresas de viagens os grandes responsáveis por causar tantos problemas contribuir para o seu agravamento? Sim, mas não apenas, há uma grande parcela de culpa dentro disso tudo que ainda temos que dividir. Mas então, a quem pertence esta triste responsabilidade? Como havíamos dito acima, a propaganda é a alma do negócio, logo ela também pode servir como difusora de ideias e ideais, não importando a origem. 
No Caso da Bahia, temos a Bahiatursa ${ }^{2}$, que é a empresa responsável pela veiculação da propaganda turística da Bahia no Brasil e no mundo. Propaganda essa que difunde todas as ideias preconceituosas além de incitar a exploração sexual e o trabalho infantil. Veremos a seguir de forma mais detalhada, uma análise que demonstra e discute as consequências que os anúncios publicitários expostos na televisão, especificamente, provocaram e provocam a curto e longo prazo, no imaginário dos turistas e na sociedade como um todo.

\section{Vem ver o que a baiana tem}

O turismo sexual, ou pornoturismo como também é chamado, se trata de um segmento não reconhecido que age dentro do turismo convencional. É um problema que afeta a vários países em todo mundo, geralmente os mais pobres, como os do leste asiático (Tailândia, Filipinas) e os da América latina, como o Brasil.

De acordo com Silva, em seu artigo "Turismo sexual, prostituição e gênero: Uma discussão teórica”, o turismo sexual se deve a uma atividade turística sem planejamento. Problemas econômicos e sociais das populações de baixa renda são os principais motivos para mulheres e crianças adentrarem para o mundo do "prostiturismo". Essas mulheres acreditam que através do envolvimento com os turistas estrangeiros, irão encontrar o seu príncipe encantado, o qual livrará elas da vida de pobreza e sofrimento. Buscam esta alternativa como uma tentativa de rápida ascensão social. Essa relação é classificada como "namoro de verão", com um tom romântico, onde o turista se encontra com a sonhada mulata brasileira que tanto ouve falar em sua terra natal e a nativa com a sua possível salvação.

Além do conto de fadas que algumas acreditam poder viver, há também o grupo de mulheres que se encontram em tal situação por necessidade, como estratégia de vida e forma de sustento, movidas pela falta de escolaridade, desemprego e exclusão social.

Por uma outra ótica, a do financeiro, podemos observar o turismo sexual como uma relação comercial. O turista como o cliente e a mulher baiana como a prestadora do serviço, estabelecendo-se assim uma hierarquia verticalizada, onde quem paga manda e desmanda em quem recebe. Este modelo de relação de hierarquia, historicamente, se assemelha muito com a relação patrão x empregado, definindo de certa forma lugares como o do Rico(turista)

\footnotetext{
${ }^{2}$ Empresa de turismo da Bahia S/A
} 
e do pobre(mulher baiana). No entanto, a semelhança com os aspectos da escravidão e do descobrimento do país é bem maior.

Em sua maioria, os turistas, geralmente da Europa, provem da etnia caucasiana, ou seja, branca, claro que havendo suas exceções. A busca por mulheres mulatas é o que prevalece entre o gosto da maioria dos estrangeiros, mulatas estas que tem origem pobre e da periferia. O paradigma dual que aqui se estabelece rememora a estrutura dos tempos da escravidão, onde o nobre dono de escravos abusava sexualmente de suas escravas domésticas, as mucamas. Nas duas situações, a mulher, colocada em um plano submisso, temia pela sua morte a mando do seu senhor caso não fizesse sua vontade nos tempos antigos, enquanto hoje, as mulheres que fazem parte desse sistema temem pelo mesmo mal, mas que pode ser decretado pela sociedade capitalista, caso não tenham dinheiro para sobreviver.

Indo mais além na historia, podemos observar a dinâmica entre o europeu e os índios na época do descobrimento do brasil. Como descreveu Caminha em sua carta ao rei, as índias andavam livremente com suas "vergonhas de fora, belas vergonhas que qualquer europeia gostaria de ter". Aproveitando da inocências das índias e da boa vontade dos índios em agradar os visitantes, estes ofereciam suas mulheres aos colonizadores, que as usaram para suprir suas fantasias sexuais.

A partir do mito dito na carta de Pero Vaz e de relatos da escravidão, não apenas no Brasil, é que surge o mito da mulata, que é colocada como mulher de apetite sexual incontrolável e possuidora de "vergonhas" avantajadas. Não só por isso claro. Alguns turista relatam que preferem as mulatas brasileiras por uma questão de dependência delas com eles, por apresentarem um perfil de submissão e serem mais amáveis do que as mulheres europeias, mais independentes.

O perfil dessas mulheres que fazem parte do esquema do turismo sexual é em sua maior parte o mesmo: De baixa renda, habitante das classes D e E, analfabeta, desempregada, residente de periferia e com idade média entre 13 e 24 anos. Comumente também são vítimas de violência familiar e sexual. São aliciadas pelos agentes indiretos do sistema, como porteiro de prédios, taxistas, guias turísticos, donos de bares, restaurantes, agentes de viagem além dos tradicionais cafetões e cafetinas. 
Por outro lado, o perfil dos turistas apresenta um contraste visível com relação ao de suas "amantes": Costumam passar de 4 a 15 dias no local, possuem idade média entre 25 e 60 anos, empregados em profissões regulares com renda mensal de aproximadamente $\$ 2000$ dólares, casados. Tem como país de origem principalmente a Alemanha, Holanda, França, EUA, Itália, Grã-Bretanha, Dinamarca, Portugal, Espanha e Suíça, sendo EUA, França, Itália e Portugal o que mais enviam turistas para a Bahia, totalizando um percentual de $42,9 \%$ do total, segundo dados da secretaria de turismo do estado da Bahia (2010).

\begin{tabular}{|l|c|r|}
\hline \multicolumn{1}{|c|}{ País emissor } & Participação (\%) & N $^{\circ}$ absoluto \\
\hline Estados Unidos & 12.3 & $\mathbf{6 3 . 2 2 2}$ \\
\hline França & 10,9 & $\mathbf{5 6 . 0 2 6}$ \\
\hline Itália & 10 & $\mathbf{5 1 . 4 0 0}$ \\
\hline Portugal & $\mathbf{9 , 8}$ & $\mathbf{5 0 . 3 7 2}$ \\
\hline Alemanha & $\mathbf{8 , 5}$ & $\mathbf{4 3 . 6 9 0}$ \\
\hline Espanha & $\mathbf{8 , 4}$ & $\mathbf{4 3 . 1 7 6}$ \\
\hline Argentina & $\mathbf{7 , 7}$ & $\mathbf{3 9 . 5 7 8}$ \\
\hline Inglaterra & $\mathbf{5 , 0}$ & $\mathbf{2 5 . 7 0 0}$ \\
\hline Chile & $\mathbf{4 , 5}$ & $\mathbf{2 3 . 1 3 0}$ \\
\hline Suíça & $\mathbf{2 , 3}$ & $\mathbf{1 1 . 8 2 2}$ \\
\hline Holanda & $\mathbf{2 , 0}$ & $\mathbf{1 0 . 2 8 0}$ \\
\hline Israel & 1,9 & $\mathbf{9 . 7 6 6}$ \\
\hline Canadá & 1,6 & $\mathbf{8 . 2 2 4}$ \\
\hline Bélgica & 1,2 & $\mathbf{6 . 1 6 8}$ \\
\hline Austrália & 1,2 & $\mathbf{6 . 1 6 8}$ \\
\hline Outros & 12,6 & $\mathbf{6 4 . 7 6 4}$ \\
\hline
\end{tabular}

O turismo sexual na Bahia começou a ter um aumento a partir dos anos 80. Alguns especialistas julgam que isto se deve, além da propaganda turística pejorativa, pelo aumento do vírus da AIDS em países tradicionais deste ramo turístico, como Tailândia e o Vietnam.

O nordeste é sempre mais requisitado pelos turistas que estão em buscam de sexo fácil, devido a maior demanda por essas regiões. Fortaleza e Salvador são as capitais mais requisitadas pelos adeptos deste segmento em específico. Algumas empresas chegam a oferecer pacotes de turismo sexual paralelos aos pacotes de viagens convencionais. 
Um grande chamativo também para fortalecer mais ainda este mercado é o carnaval. Transmitido mundo afora, o carnaval atrai olhares e turistas do mundo todo para poder assistir a maior festa do mundo. Apesar da grandiosidade, o que chama a atenção dessas pessoas e a possibilidade de ver aquelas mulheres fantasiadas, quase seminuas, desfilando e rebolando em plena rua. Apaixonados pelo "gingado das brasileira, em particular das baianas, esses turistas sonham com a oportunidade de poder realizar suas fantasias com essas mulatas "de outro mundo".

O trafico de mulheres é outro tema que percorre o universo do turismo sexual. Baseado nos pressupostos de regime escravo e cárcere privado e indo diretamente contra os direitos humanos, o trafico de mulheres acontece através também das visitas de alguns determinados turistas a Bahia, com objetivos ainda mais definidos. Eles vem ao país em busca de aventuras sexuais exóticas, e assim encontram as moças ingênuas em busca de uma vida melhor e melhores condições de moradia. Acabam que prometem um mundo para essas mulheres, convencendo-as a viajaram para o exterior, convictas de um casamento próximo. Porém, a realidade encontrada lá é muito diferente. São maltratadas por estes turistas, escravizadas como domesticas e até aliciadas para a prostituição. Segundo Feijó, o Brasil é o país que mais exporta mulheres para a Europa, são 75 mil ao total. Um processo que coloca a mulher em uma condição de mercadoria comercializável, inferiorizando-a e colocando-a em uma condição desumana.

O governo da Bahia toma medidas de prevenção em contraposição a este tipo de turismo, com a produção de cartilhas e a realização de seminários, que se mostram ineficazes junto a real proporção do problema.

Apesar das ações de combate, o próprio governo em sua propaganda turística, incita o turismo sexual de forma subjetiva, mostrando mulatas em enquadramentos que visam suas curvas, de preferencia as pernas e os glúteos, desconsiderando a feição desta. Dessa forma, é nítida a imagem que se quer passar da mulher baiana nesse caso: Mulher sensual, quente, de olhar sedutor e de fácil acesso aos turistas. A figura da mulata baiana é a principal imagem reproduzida dentro e fora do país como grande atrativo de turistas, usado pelo marketing da Bahiatursa.

\section{O baiano e a bahia na propaganda turística: eles existem?}


"Venha para Bahia, terra de belezas naturais, festa e muita alegria e paz", "Aqui, sua férias terão preguiça de terminar". Frases como essas são muito comuns nos anúncios publicitários divulgados pela Bahiatursa, órgão responsável pelo turismo do estado. Através dele, é perceptível a tentativa de se construir uma visão do que é a Bahia e como são os baianos. Entretanto, o que se é retratado nas peças nada mais é do que uma realidade distorcida e imperfeita da verdadeira realidade, um simulacro.

Com isso, observamos uma inversão da realidade, ou seja, um simulacro, que nada mais é do que uma cópia ou reprodução imperfeita, já que a realidade vista e lida não é a realidade vivida por todos os baianos, e sim por uma minoria. (Xavier, 2010:3)

Ainda segundo Xavier, o objetivo da bahiatursa com a imagem criada pela propaganda turística do estado produzir uma construção de uma Bahia idealizada que habita o imaginário de muitas pessoas que não tiveram outro contato com o estado que não fosse feito através de algum meio de comunicação (Xavier, 2010).

Dentro deste processo de construção de uma realidade imperfeita, às vezes inexistentes, podemos classificar em dois eixos que sustentam essa suposta realidade veiculada nos anúncios: a construção do território e a construção da identidade do individuo local.

Na maioria dos comerciais, é visível o numero de imagens mostradas das atrações turísticas da cidade de Salvador e região metropolitana, reservando alguns pouquíssimos segundo a uma imagem de paisagem do centro sul do estado, a chapada Diamantina, exclusivamente. Porém, em toda narração do comercial, a voz de fundo do narrador apresenta como se o que fosse exposto ali fosse o mais fiel retrato do estado baiano. Uma realidade distorcida.

Maria Brandão (1999) explica que tal atitude, a necessidade de se construir um território unificado - de maneira geográfica e cultural - é causa da inexistência de uma identidade nacional, e sim de grupos específicos.

Daí, a necessidade de se traçar um território geográfico reconhecido juntamente com uma cultura uniforme e um individuo comum se apresenta como forma de criar um falso sentimento de nacionalismo. No caso da Bahia, podemos chamar tal fenômeno de Soteropolitanização, que se caracteriza na ação de reduzir o estado ao território, cultura e tradição da Capital, Salvador. Soteropolitanização deriva da palavra soteropolitano, que significa cidadão nascido em Salvador, logo, a relação entre termo agente e significado. 
Outro aspecto analisado foi a forma como a Bahiatursa trata a questão da identidade do cidadão baiano. Novamente, é visível a discrepância entre o real e o idealizado pelo orgão.

Com relação a formação da identidade de um determinado grupo, Hall explica da seguinte maneira:

A identidade é definida historicamente, e não biologicamente. O sujeito assume identidades em diferentes momentos, identidades que são unificadas ao redor de um "eu" coerente. [...] A identidade plenamente unificada, segura e coerente é uma fantasia. (HALL, 2003, p.18)

Já com relação a formação do estereótipo sobre uma determinada identidade objetivada, Kotler analisa:

Um estereótipo sugere uma imagem amplamente difundida que é basicamente historicizada e simplista. É onde provoca uma atividade favorável ou desfavorável em relação à localidade. (KOTLER, 1994, p.152)

Na construção do estereótipo identitário baiano, a exotização do individuo é o primeiro passo deste processo. Individuo este que retrate fielmente todas as suas culturas e tradições, sejam na sua forma de se vestir, de agir, ou de se comunicar. "Oxente", "Meu Rei" são palavras que não figuram entre o linguajar cotidiano no estado. Porém, ficou famoso por serem usados eventualmente pelos artistas da musica baiana como forma de diferenciar o seu sotaque - Como os músicos Caetano Veloso e Gilberto Gil nos tempos do Tropicalismo ${ }^{3}$ - e foi reproduzido pelos setores da mídia e pelo marketing turístico justamente por ser algo incomum é exclusivo.

O perfil do cidadão que é mostrado nas propagandas turísticas é o de um ser humamo mulato ou negro, sempre alegre e sorridente, com vestimentas típicas de religiões afro, despreocupados com a própria vida - o que subjetivamente denota vadiagem, reforçando o estereótipo da preguiça, a ser tratado mais a frente - e ignorantes que não possuem conhecimento e estudo, por ocuparem sempre subempregos ao longo dos comerciais. Todos esses pensamentos reproduzidos pelo setor de comunicação do turismo baiano provêm da era colonial, onde essas ideias eram anexadas aos escravos, como forma de inferiorizar os negros da época e também como forma de racismo.

\footnotetext{
${ }^{3}$ Tropicalismo ou Movimento Tropicalista era um movimento cultural brasileiro que surgiu sob a influencia das correntes artísticas de vanguarda e a cultura pop nacional e estrangeira (como o pop-rock e o concrestismo).
} 
Um exemplo de que esses pensamentos permeiam o senso comum foi o caso do exprofessor da Faculdade de Medicina da UFBA, Antônio Natalino, que atribuiu o baixo desenvolvimento de suas alunos no ENADE - Exame que mede a qualidade dos cursos de graduação no Brasil - a falta de neurônios do povo baiano. Como Afirmou o professor em entrevista ao site Terra (2008), "Não temos aquele desenvolvimento que poderíamos ter. Se comparados com os estados do sul, vemos que a imigração japonesa, italiana e alemã foram excelentes para o país." E ainda completa: "O símbolo da Bahia, o berimbau, e um instrumento para pessoas pouco inteligentes, com poucos neurônios. Ele tem uma corda só e não precisa de muitas combinações musicais."

Outro traço importante que é explorado pela Bahiatursa na formação da identidade é a de que nós baianos vivemos em festa. Mattoso (1992, p.205) apresenta um argumento interessante que pode justificar o surgimento do mito da festa constante na Bahia. Segundo Mattoso, a estruturas das casas em Salvador no século XIX continham uma sala de visita ampla para a socialização dos anfitriões com seus convidados - Surge ai também a imagem do sujeito acolhedor, de porás abertas para os turista - . No calendário atual de festa do estado, a Bahia possui, além do carnaval e dos festivais o inicio do ano, 2 festas institucionais ( Independência da Bahia em 2 de julho e a do Brasil, em 7 de setembro), além dos feriados religiosos católicos e dos culto afro.

O conceito de festa constante foi ressignificado recentemente, com o advento da festa do carnaval, considerada a "maior festa de rua do mundo". Em consequência, o novo rótulo de "profissionais em fazerem festa" foi atrelado a figura do ser nativo. Daí também recorre parte do estereótipo da preguiça, a partir o pensamento de que um povo que vive em festa, não trabalha.

Dos estereotipos talvez o pior e mais cruel, o mito da preguiça que recai sobre a sociedade baiana é o que mais incomoda, e ainda é o mais explorados não só pelo turismo do estado, mas pela mídia sulista em geral. "Baiano vive na rede", "baiano é lezado (sic)", "baiano é povo que só dorme" são os preconceitos geralmente reproduzidos pela mídia em forma de humor, como também pelas populações de outros estados, com São Paulo, principalmente, devido a grande migração de nordestinos para o estado.

Tal conceito surge também na era colonial como forma de racismo sobre os escravos. Os senhores de engenho da época taxavam seus escravos como preguiçoso como estratégia de forçar mais ainda o trabalho para a produção de aumento de capital. Alegações estas 
embasadas no modo capitalista de produção, onde um indivíduo enriquece a partir da exploração pelo trabalho de outros indivíduos.

Outra explicação de cunho preconceito com relação a preguiça, é a justificativa da preguiça do povo baiano através da alimentação a base de Dendê. O Dendê é o oléo utilizado para preparar boa parte dos pratos típicos da culinária baiana, como o vatapá, caruru, acarajé, moquecas, etc. Após a ingestão de pratos que contenham dendê na receita, uma sensação de bem estar e relaxamento nos músculos é sentida, devido a substancias existentes em sua composição. O grande problema é generalizar a alimentação dos baianos a apenas pratos típicos locais, quando a alimentação dos cidadãos é semelhante a da sociedade brasileira em geral.

Tal circunstancia ocorre por dois principais motivos: primeiramente que nas anúncios publicitários divulgados pelo estado a culinária típica baiana é a única a ser mostrada, pressupondo que ela configura a base da alimentação do estado, negando assim, todos os outros traços da culinárias nacional e também baiana do interior do estado, considerando-as inexistentes. Em segundo lugar, a visão estereotipada que os turistas - induzidos pela propaganda a acreditar que Bahia se resume a cultura soteropolitana - reproduzem em seus ambientes locais, por ficarem restritos a cultura da capital, desconhecendo os traços culturais do restante do estado.

Enfim, em momento queremos afirmar que não existem personagens como aqueles mostrados na propaganda turística baiana, até porque todo generalismo está fadado ao ostracismo. O que quisemos mostrar é que existe uma gama muito maior de cultura, de costumes e de identidades dentro do território chamado Bahia.

Claro que há pessoas que se encaixam na definição distorcida pela Bahiatursa, são cidadãos que tem seu imaginário social e individual permeado pelas ideias difundidas através dos meios de comunicação, nesse caso, os anúncios divulgados pela Bahiatursa. Tal fenômeno acontece como disfunção de um nacionalismo exagerado e da necessidade que alguns indivíduos tem de se reconhecer com o território onde vivem. Como os media, em especifico, a televisão, é o principal meio de formação e informação dessas pessoas, é a parir deste conteúdo que esses indivíduos extraem os traços da identidade a ser construída. Tornandose um ser portador de uma falsa identidade, ou sem identidade própria definida. 


\section{Os negros baianos na propaganda}

Racismo é um tema problemático em todo o mundo. Os séculos passados nos deixaram um legado de tristeza que apesar disso, não deve ser esquecido, muito menos reproduzido novamente. No Brasil não foi diferente, um dos países que mais recebeu escravos africanos para trabalhar nas lavouras de açúcar no período colonial.

A Bahia, dentro deste contexto, era o principal porto de chegada desses escravos, que mesmo após o fim da escravidão continuaram pela região, do recôncavo baiano e do sul do estado principalmente. Como consequência, a sociedade baiana pode adotar traços desses povos vindos do outro continente, uma miscigenação cultural que perpassa pela culinária, religião, estilo e raça, logo que todo baiano tem uma mistura onde se encontra também a raiz negra.

Apesar da beleza cultural e do legado que os afrodescendentes trouxeram para a Bahia, a mídia publicitária age de maneira torpe para usurpar o que há de bom nessa cultura e ao mesmo tempo criminalizar esses cidadãos. Na comercial televisivo, o negro é colocado como ser cultural e sua cultura é vendida como atrativo turístico. Vende-se a comida, o jeito de ser, a arte (capoeira) e os costumes religiosos como algo exótico. No entanto, o individuo negro em si, não só é criminalizado, como também é posto na propaganda apenas como os trabalhadores em subempregos, quando não colocados como desocupados e festeiros, estereótipos já debatidos. Tal cena faz alusão subjetiva aos tempos da escravidão, onde os negros viviam num sistema de servidão aos seus patrões - que se evoluíram (ou não) da forma escravagistas para patrões de ideiais capitalistas -.

O preconceito contido na peça publicitária não está contido necessariamente na persona do negro como baiano, logo que boa parte da população do estado é de etnia negra ou parda, e sim no personagem do turista, que é SEMPRE representado por um individuo de cor branca, como se a população negra não tivesse capital financeiro suficiente para realizar uma viagem turística.

Preconceitos estes que são difundidos pela Bahiatursa em todos os comerciais analisados durante o período citado (2007-2013), mostrando que tal atitude não se trata de um erro do comercial ou da ação de uma produtora audiovisual especifica que prestasse serviço ao órgão, mas sim é a mais clara ideia que a empresa insiste em passar. 


\section{Prostituiço, trabalho infantil e realojamento na televisãoã}

Os problemas que tem enfoque na população infantil no estado também são reforçados pelo conteúdo da propaganda de turismo do governo. Questões como trabalho infantil e prostituição são tratados de forma que o telespectador se acostume com o que está sendo dito sem perceber seu real significado.

Em vários dingles (vídeos promocionais de aproximadamente 30 segundos) crianças são mostradas realizando algumas atividades que as deixam felizes com o narrador ao fundo dizendo "repare só, é lindo" como se a atividade realizada fosse um futuro desejável para a criança em questão. Explicitando também a visão do trabalho infantil, quando demonstra esses pequenos indivíduos como experiente em atividades de servir aos turistas.

Outro ponto agravante é o uso apelativo dessas crianças nos anúncios, sabendo o quanto a exploração infantil e a busca por turismo sexual no estado constante. Segundo dados do IBGE, $60 \%$ das crianças que são vitimas do turismo sexual tem entre 13 e 16 anos, mas por volta dos 11 anos é a idade em que a maioria delas começa a serem aliciadas e prostituidas. No Brasil há em média, 500 mil crianças no ramo de prostituição, sendo que $20 \%$ delas se deve ao turismo sexual.

Podemos caracterizar esse número considerável pela falta de educação básica no páis, principalmente no estado, que ocupa uma das piores posições nos índices educacionais do Brasil.

\section{Conclusiones}

Ao fim dessa jornadas de discussões e análises, tivemos a oportunidades de ver com mais calma o preconceitos e estereotipos que a Bahiatursa reproduz em seus informes publicitários direcionados á população dentro e fora do país.

Podemos elencar de forma clara, quais são estes rótulos e de que forma eles são difundidos no espaço televisivo publicitário do estado. A visão difundida nas propagandas pode ser caracterizada como uma "comunidade imaginada" da Bahia.(ANDERSON, 1993) 
Tais ideias se assemelham com as mesmas difundidas pela elite baiana no tempo do Brasil Colonia. Hojee las são defendidas pelo governo, e continuam sendo difundidas pela elite baiana, só que agora na figura do empresariado local.

Seria muito comum se um turista se espantasse e se encantasse com a cultura fora da capital. Seria bom para eles compreenderem que na mesma terra do verão, Praia, sol e mar, existe o planalto da conquista ao sul do estado, que poderia muito bem ser a terra do inverno, com temperaturas baixas quase $o$ ano todo.

É preciso entender que a Bahia é muito mais que Salvador. Seria bom também que o governo do estado soubesse diferenciar o estado da capital nas suas propagandas, e não reduzi-lo. Mostrar a diversidade de culturas, povos e costumes que o estado agrega, que dependendo da região, seja ela norte ou sul, os costumes se transformam e se reinventam. Mostrar que nem tudo é Praia, como a maioria dos turistas acham.

A Bahia é um dos únicos estado no país que possui uma variação lingüística (sotaque) dentro de seu proprio territorio, onde as vezes um vocabulo dito na região sul do estado seria incompreendido no agreste do sertão baiano. Entender o que é a Bahia, é saber que "oxente meu rei" não é uma indagação, muito menos uma expressão usada por nós, poderia ser talvez um isullto preconceituso. Isso sim é a Bahia, não o que a Bahiatursa finge dizer mostrar.

\section{Bibliografía}

ANDERSON, Benedict. Nação e consiência nacional. São Paulo. Ed. Ática, 1989.

DINIZ, J. Pericles. Questões de raça na identidade baiana. Quinto Encontro de Estudos Multidisciplinares em Cultura (V ENECULT). Salvador. 2009.

FEIJÒ, Fernando C.;CALAZANS, Flávio M. A. A imagem internacional do turismo sexual no Brasil: O prostiturismo no marketing turístico. Centro de Paula Souza, São Paulo. 2002.

FILHO, Antonio J. D. As mulatas que não estão no mapa. In: Cadernos Pagu (6/7) 1996, p. 51-66.

HALL, Stuart. Identidades na pós Modernidade. Rio de Janeiro, DP\&A.2003. 
KOTLER, Philip. Marketing Público: Como atrair Investimentos, empresas e turismo para cidades, regiões, estados e países. São Paulo, Makron books, 1994.

KRONES, J. M. Turismo e baianidade: A construção da marca "BAHIA". Terceiro Encontro de Estudos Multidisciplinares em Cultura (III ENECULT). Salvador. 2007

MADEIRA, Fabiane. Professor atribui baixa nota do ENADE ao "QI dos baianos". 2008. Disponivel em: http://noticias.terra.com.br/educacao/interna/0,0l2858408El8266,00.HTML

MELO, Cristina T. Construção Identitária da Bahia. In: Linguagem em (Dis)curso - LemD, Tubarão, v. 6, n. 1, p. 29-44, jan/abr. 2006.

OLIVEIRA, Rodrigo B. A "comunidade imaginada" Bahia e a publicidade da Bahiatursa; Um enfoque sobre o estereótipo da preguiça. In: Carderno Virtual de turismo, vol. 6, num. 3, 2006, p.54-63. Universidade Ferderal do Rio de Janeiro. Rio de janeiro.

PEREZ, Clotilde. Condições Antrpossemióticas do negro na publicidade contemporânea. In: BATISTA, Leonardo; LEITE, Francisco (orgs.). O negro nos espaços Publicitários brasileiros: Perspectivas Conteporâneas em Diálogo.Escola de Comunicações e artes/USP: Coordenação de assuntos da população negra. São Paulo, SP.2011, p. 61-84.

PISCITELLI, Adriana. "Sexo Tropical": Comentários sobre Gênero e "Raça" em alguns textos da mídia brasileira. In: Cardernos Pagu (6-7), 1996, p. 9-34.

REITER, Bernd.; DIAS, Rita de C. Reforma educacional, exclusão e racismo na Bahia. In: Gestão e ação. V.8, n. 1. Salvador, jan./abr. 2005. P.97-116.

ROSO, A.; STREY, M. N.; GUARESCHY, P.; BUENO, S. M. N. Cultura e ideologia: a mídia revelando estereótipos raciais e de gênero. In: Psicologia \& Sociedade; 14(2): 74-94; jul./dez. 2002.

SANTOS, Claudia E. F. "Passaporte na mão e camisinha na outra: a imagem da mulher brasileira e o turismo sexual na cidade de Salvador". XVI Encontro Nacional de Estudos Populacionais, ABEP. Caxambú-MG. 2008

SILVA, Dilma de Melo. A imagen do negro no espaço publicitário. In: BATISTA, Leonardo; LEITE, Francisco (orgs.). O negro nos espaços Publicitários brasileiros: Perspectivas Conteporâneas em Diálogo.Escola de Comunicações e artes/USP: Coordenação de assuntos da população negra. São Paulo, SP.2011, p.19-27.

SILVA, Tatiana A. Turismo sexual, prostituição e gênero: Uma discussão Teórica. XII Seminário Nacional e III Seminário Internacional Mulher e Literatura. Salvador. 2008. 
XAVIER, Antonio.; BORGES, N.; SANTOS, Ana P.; GUEDES, Rafael. "Mapas urbanos: simulacro, baianidade e reafirmação de estereotipos.XII Congresso de Ciencias da Comunicação da Região Nordeste (INTERCOM). Campina Grande. 2010.

ZANLORENZI, E. O Mito da Preguiça Baiana. Tese de doutoramento, ano de obtenção 1998.

\section{Forma de citar este artículo en bibliografías}

Dantas, L. E. (2013): "Oxente meu rei: uma análise dos preconceitos reproduzidos pela propaganda turística do governo da Bahia", en Revista PANGEA, 4, páginas 110 a 125. Red Académica Iberoamericana de Comunicación. Recuperado el de de 2 de: http://www.revistapangea.org 